\title{
Long-Term Patient-Aspect Outcomes of the Single-Port Laparoscopic Cholecystectomy
}

\author{
Ju Yeon Kim, Young Hoon Roh, Minchan Kim \\ Department of Surgery, Dong-A University College of Medicine, Busan, Korea \\ Email: gsryh@dau.ac.kr
}

How to cite this paper: Kim, J.Y., Roh, Y.H. and Kim. M. (2018) Long-Term Patient-Aspect Outcomes of the Single-Port Laparoscopic Cholecystectomy. Open Journal of Gastroenterology, 8, 245-254. https://doi.org/10.4236/ojgas.2018.86027

Received: April 15, 2018

Accepted: June 26, 2018

Published: June 29, 2018

Copyright ( 92018 by authors and Scientific Research Publishing Inc. This work is licensed under the Creative Commons Attribution International License (CC BY 4.0).

http://creativecommons.org/licenses/by/4.0/

\begin{abstract}
Background: Single port laparoscopic cholecystectomy (SPLC) is a widely performed advanced technique in laparoscopic surgery which has many benefits compare to conventional three port laparoscopic cholecystectomy (TPLC). The purpose of this study was to compare the patients' satisfaction of SPLC and TPLC after one year of operation by using questionnaire which not only objective factors such as results of operation and hospital days but also subjective factor such as social and cosmetic quality of life. Materials and Methods: This study analyzed the data of 74 patients $($ SPLC $=42$, TPLC $=32$ ) who underwent the laparoscopic cholecystectomy between March and July 2013. The patients were asked to complete a patient-assessment questionnaire measuring the postoperative social and cosmetic quality-of-life values at the 12-month mark. Results: Statistically significant differences in the age, sex distribution, and body mass index are absent between the two groups. All the average scores of the different parameters of the social-activity aspect-satisfaction with physical condition, limitation of nutrition, stamina, postoperative pain level, returning to social life, impairment of social life, degree of complications, and cost-effectiveness of the surgery-are not statistically significant in both groups. Alternatively, all the results of the cosmetic aspect-scar influence on charms $(p<0.001)$, satisfaction regarding scar appearance $(p=$ $0.015)$, and patient's score of scars $(p<0.001)$ - show statistically significant differences. Conclusion: The SPLC is a safe and an attractive approach regarding the patients of this study. It offers a more effective cosmetic result that may be conveyed by a greater patient satisfaction.
\end{abstract}

\section{Keywords}

Long-Term Outcome, SPLC, Patients, Satisfaction 


\section{Introduction}

Single-incision laparoscopic procedures have evolved gradually to include a multitude of various surgeries. The current literature documents the usage of single-incision or single-port access surgery for cholecystectomies, adrenalectomies, splenectomies, appendectomies, herniorrhaphies, bariatrics, and colon surgery [1] [2] [3]. Navarra et al. [4] performed the first single-incision laparoscopic cholecystectomy in 1995. Since that time, the single-port laparoscopic cholecystectomy (SPLC) has been a novel technique, comparable with the conventional multi-incision laparoscopic cholecystectomy (CLC), for the uncomplicated, benign gall bladder (GB) diseases with respect to the safety and efficacy [5] [6] [7]. With the increasing patient demand for enhanced cosmetic outcomes, the SPLC results in a single and smaller wound, thereby satisfying the patient. In addition to the SPLC cosmetic advantage, the potential benefits of reduced postoperative pain and faster recovery have been reported [8] [9].

The patient satisfaction, however, has only been estimated from the operator perspective in many studies, and the operative factors are not directly associated with the patient demands. The capacity of the operator-estimated operative factors regarding the revelation of the patient quality of life (QoL) is questionable. The cosmetic outcomes are not easily objectified, and if they can be objectified by researchers, they cannot reveal the patient satisfaction directly. The questionnaire is one of the most effective tools for the assessment of the patient satisfaction; therefore, the authors attempted to investigate the actual patient satisfaction using a questionnaire that was answered by the patients themselves. Additionally, if the questionnaire is answered for a long-term follow-up, the responses can reflect the actual long-term outcomes according to the patient view.

This study comprises a long-term follow-up study for which the questionnaire tool is employed to compare the SPLC with the three-port laparoscopic cholecystectomy (TPLC). The long-term effectiveness of the patient view is the primary interest of the present study, rather than the SPLC efficacy in the immediate postoperative period. To the authors' knowledge, a dearth of the patient-view studies exists relative to those of the operator view, especially regarding the long-term follow-up. The intention of this study comprises demonstrations of the difference between the patient and operator views, and whether the SPLC or the TPLC is ultimately more satisfactory for the patients over the long term after the operation.

\section{Materials and Methods}

\subsection{Patients}

The data of 74 patients who had undergone the laparoscopic cholecystectomy between March and July 2013 were analyzed for this study. When determining sample size, we considered about the loss to long term follow-up (approximately $5 \%$ in general) for statistical reliability. All the surgeries were performed by a 
single surgeon at a single medical center. For the research investigation, the two groups, SPLC $(n=42)$ and TPLC $(n=32)$, were separated. The preoperative demographic characteristics and the postoperative outcomes of the two groups were compared. The clinical and operation information consist of the patient sex, age, height, weight, body mass index (BMI), operation time, complication number, postoperative hospital days, and postoperative follow-up interval.

\subsection{Surgical Procedure}

The details of the surgical procedure have been described previously [10]. The study preparation required all the patients to be placed in the supine position under general anesthesia. The operator and the first assistant were on the left side of the patient. After a midline transumbilical incision of $2.5 \mathrm{~cm}$ was made in the lithotomy position, camera and surgical devices were inserted using the OCTO Port multichannel port (Dalim Surg Net, South Korea). For the surgical devices, the single-port articulating instruments and the conventional laparoscopic instruments that are used in the conventional three-port surgery, including the $30^{\circ}$ angled rigid laparoscope with the $5-\mathrm{mm}$ diameter that is mainly used for cameras, were combined. The gall bladder was dissected after the exposure of the Calot's triangle area, followed by the ligation of the cystic duct with the 10-mm Hem-o-lok clip (Weck Closure Systems, U.S.) and the ligation of the cystic artery with the 5-mm Hem-o-lok clip (Weck Closure Systems, U.S.). Then, the gall bladder was separated from the liver bed and removed directly through the port site without the catch bag. An additional port was inserted when it was dangerous to only use the SPLC for the surgery execution, or if it was difficult to dissect the adjacent structures. A drain was not inserted after the SPLC operation. The drain insertion depends on the port number and the inflammation grade.

\subsection{Questionnaire}

We developed an our own patient assessment questionnaire including social and cosmetic categories which considered known quality of life index such as Short Form Health Survey (SF-36) and other studies of cosmetic results of SPLC. The patients were asked to complete the questionnaire that measures the social and cosmetic QoL criteria 12 months after the operation. All the subjects were interviewed personally and the questionnaire was filled out individually. When patients completed the questionnaire, they freely expressed their opinions at isolated space, and the doctor was not involved at all. The ethical committee of the institution approved the study.

The body weight and height were measured to evaluate the BMI aspect that significantly influences the QoL and postoperative complications [11] [12]. The social-aspect questionnaire consists of the following 8 categories: 1 . Satisfaction with physical condition; 2. Limitation on nutrition; 3 . Stamina; 4. Postoperative pain level; 5. Returning to social life; 6. Impairment of social life; 7. Degree of 
complications; and 8. Cost-effectiveness of surgery. The cosmetic-aspect questionnaire consists of the following 4 categories: 1 . Influence of scars on charms; 2. Satisfaction with appearance of scars; 3. Patient's score of scars; and 4. Influence of scars on everyday life. Each category question can be given four or five possible responses (Appendix 1).

\subsection{Statistical Analysis}

The continuous data were presented as the mean \pm standard deviation. To determine the significant factors as the port number was increased, the linear-by-linear association and the Jonckheere-Terpstra test were used for both the categorical and continuous numerical data. To exclude the confounding factors of the additional-port usage during the operation, the one-port and three-port operations, exclusive of the two- or four-port usage, were compared separately, for which the Student's t-test was used. To identify the risk factors that affected the complications, the logistic-regression analysis was used. Based on the results of the univariate analysis, each of the questionnaire items that showed significantly different results with the increasing port number was reanalyzed using the multiple-regression test, thereby identifying the variables that caused the differences. The statistical computations were performed using the SPSS Statistics software (version 20; IBM, U.S.).

\section{Results}

This study comprises the total of 74 patients $($ SPLC $=42$, TPLC $=32$ ). There are no statistically significant differences in the age, sex distribution, or BMI (Table 1). According to the preoperative diagnosis, the GB stone $(n=19)$ is the most common condition in the SPLC sample, followed by the GB polyp $(n=18)$, acute cholecystitis $(n=4)$, and GB empyema $(n=1)$. In the TPLC sample, the most common diagnosis is the acute cholecystitis $(n=16)$, followed by the GB stone $(n=9)$, GB empyema $(n=4)$, and GB polyp $(n=3)$. The operation time of the SPLC group is slightly shorter, and this is the only statistically significant difference between the two groups, with the averages of $46.9 \pm 1.6 \mathrm{~min}$ for the SPLC group and $61.3 \pm 4.2 \mathrm{~min}$ for the TPLC group $(p=0.005)$.

Postoperative complications occurred in 1 case of the SPLC group (umbilical discharge) and 2 cases of the TPLC group (umbilical discharge and port-site seroma); the patients recovered with the provision of supportive care during and after the hospital stay. The postoperative hospital days and the postoperative follow-up interval of the two groups do not differ significantly. Due to the national insurance system of South Korea, the typical hospital stay of the LC patients is more than 2 days.

The comparison of the patient-questionnaire information and answers between the two groups is presented in Table 2. All the average scores of the different parameters of the social-activity aspect are as follows: 1 . Satisfaction with physical condition $(p=0.975) ; 2$. Limitation on nutrition $(p=0.820)$; 3 . Stamina 
Table 1. Characteristics of patients.

\begin{tabular}{lccc}
\hline \multicolumn{1}{c}{ Port number (total $\mathrm{n}=74)$} & $1(\mathrm{n}=42)$ & $3(\mathrm{n}=32)$ & p-value \\
\hline Male sex (\%) & $18(42.9)$ & $12(37.5)$ & 0.688 \\
Age, years & $55.1 \pm 2.1$ & $56.6 \pm 3.3$ & 0.677 \\
Height $(\mathrm{cm})$ & $161.2 \pm 2.8$ & $164.2 \pm 1.7$ & 0.458 \\
Weight $(\mathrm{kg})$ & $61.9 \pm 1.9$ & $62.2 \pm 1.9$ & 0.917 \\
BMI & $26.5 \pm 3.5$ & $23.0 \pm 0.5$ & 0.451 \\
Diagnosis & & & \\
$\quad$ GB polyp & 18 & 3 & \\
GB stone & 19 & 9 & \\
Acute cholecystitis & 4 & 16 & \\
GB Empyema & 1 & 4 & 0.005 \\
Operation time (min) & $46.9 \pm 1.6$ & $61.3 \pm 4.2$ & 0.358 \\
Number of complications & 1 & 2 & 0.167 \\
Hospital days after operation (days) & $2.0 \pm 0.1$ & $2.4 \pm 0.2$ & \\
Follow up interval after operation (days) & $361.2 \pm 1.8$ & $364.8 \pm 2.7$ & \\
\hline
\end{tabular}

GB: Gallbladder, BMI: Body Mass Index.

Table 2. Analysis on number of ports and risk of complications.

\begin{tabular}{|c|c|c|}
\hline Items of questionnaire & 1 Port vs 3 ports (p-value) & Risk of Complications ${ }^{*}$ \\
\hline Sex & 0.688 & \\
\hline Age & 0.677 & \\
\hline Height $(\mathrm{cm})$ & 0.458 & \\
\hline Weight (kg) & 0.917 & 0.035 \\
\hline BMI & 0.451 & \\
\hline Social 1 & 0.975 & \\
\hline 2 & 0.820 & \\
\hline 3 & 0.600 & \\
\hline 4 & 0.629 & \\
\hline 5 & 0.730 & \\
\hline 6 & 0.670 & \\
\hline 7 & 0.742 & \\
\hline 8 & 00.690 & \\
\hline Cosmetic 1 & $<0.001$ & \\
\hline 2 & 0.015 & \\
\hline 3 & $<0.001$ & \\
\hline 4 & 0.235 & \\
\hline Operation time & 0.005 & \\
\hline Complications & 0.358 & \\
\hline Drain & $<0.001$ & 0.044 \\
\hline Hospital days after operation & 0.050 & \\
\hline Follow up interval after operation & 0.167 & \\
\hline
\end{tabular}

${ }^{\star}$ Analyzed by multivariate logistic regression. 
$(p=0.600) ; 4$. Postoperative pain level $(p=0.629) ; 5$. Returning to social life ( $p=$ $0.730)$; 6. Impairment of social life $(p=0.670)$; 7. Degree of complications $(p=$ $0.742)$; and 8 . Cost-effectiveness of surgery $(p=0.690)$. These average scores are not statistically significant in both groups.

Alternatively, as shown in Table 2, the cosmetic-aspect results regarding the first three questions show statistically significant differences, as follows: 1 . Influence of scars on charms $(p<0.001)$; 2 Satisfaction with appearance of scars ( $p$ $=0.015)$; and 3. Patient's score of scars $(p<0.001)$. Whereas the results of the last question, 4 . Influence of scars on everyday life $(p=0.235)$, are statistically similar in both groups, as is also shown in Table 2.

\section{Discussion}

The evolution of the gallbladder surgery from the Langenbuch's first cholecystectomy with the hospital stay of 6 weeks into the day-care specialty following the LC introduction is indeed fascinating [13]. The main thrust throughout the history of the cholecystectomy has been the pain reduction and the cosmesis improvement, and the notion of the scarless surgery has mainly led to the increased patient acceptance of the procedures [14].

Potential benefits regarding the decreased port number for the completion of the laparoscopic procedures compared with that of the traditional multiport approach have been reported. A recent study demonstrated that the SPLC produced a superior cosmetic result, less pain, and faster recovery in the selected patients [15] [16] [17] [18]. Other studies also present the superior cosmetic results [19] [20] [21] and the decreased morbidity, primarily regarding the postoperative pain [9] [17] [18], as the projected benefits of the SPLC over the CLC [22]. Only a number of studies, however, have compared the patient-aspect benefit between the SPLC and CLC operations.

The present study explored the patient perception of the postoperative social and cosmetic results. One important result of this study is the greater satisfaction of the SPLC-patient group regarding the scars. The various associated factors of the social-activity aspect are not statistically significant, while the cosmetic score of the SPLC group is significantly higher. It is probable that this result will lead to an increasing number of people favoring the SPLC if they are indicated and can choose, because the other factors such as pain, complications, and hospital days are comparable; moreover, the postoperative cosmetic benefits become much more important for the patient view compared with the doctor view that perceives scars as merely consequential surgical wounds. Therefore, this scar problem needs to be considered from a new perspective. If only the predicted surgical achievement and the other-patient preoperative conditions are similar, the cosmetic aspect should be considered as an important criterion in the selection of the operation method.

However, the controversy regarding the SPLC cosmetic effect is ongoing. Ma et al. found that the SPLC benefits regarding the patient overall and cosmetic 
satisfaction are not significant [23]. Also, Garg et al. revealed that the patient perceptions regarding the cosmetic outcome after the SPLC and the CLC are similar in both groups [24]. Therefore, the results of this study should be considered with a large number of patients using the prospective randomized and blinded method.

Since the indications for SPLC are not yet clearly established, the application of SPLC is still limited in all patients. Our indication for SPLC was polyp disease and mild cholecystitis with gall bladder stone (no right-upper-quadrant abdominal tenderness in physical examination, no gall bladder wall thickening in image study) whereas TPLC was applied to previous laparoscopic surgery indication [10]. With difference of patient selection, SPLC was mainly operated on patients with mild disease and that was easier to perform than TPLC. Furthermore, this study carried the patients' information from only one skillful surgeon who did 500 cases of SPLC until now. Some studies have shown that an operating time decreased according to the increase of the surgeon's experience [25] [26] [27].

Several study limitations need to be considered here. While the patient-completed questionnaire was developed and provided to all the patients for the objective measuring of their social and cosmetic satisfaction, the self-developed questions were not validated, and this is in contrast to the SF-36 or the Gastrointestinal Quality of Life Index (GIQLI), which are well-validated QoL-analysis tools. The authors just obtained the data regarding the patient perceptions of the social and cosmetic outcomes, but these data do not represent the entirety of the patient-aspect long-term outcomes. Furthermore, during the question answering, the patients were not shown or did not experience the SPLC and TPLC postoperative results simultaneously, so they answered the questions according to their highly subjective perceptions without a comparison of both operations. In general, the public consider the single-incision surgeries as a more advanced, less invasive, and more cosmetically pleasing method, and this might have influenced the patient answers.

\section{Conclusion}

The results of this study show that the SPLC-patient perceptions regarding the postoperative cosmetic outcomes are more favorable; alternatively, though, the various parameters of the social-activity aspect are not statistically significant, and this means that the SPLC offers a more favorable cosmetic result, which may be conveyed by the greater patient satisfaction. As the postoperative cosmetic outcomes represent a much more important event with respect to the patient view compared with the doctor view, the cosmetic aspect should be considered as an important criterion in the selection of the operation method.

\section{Funding}

This work was supported by the Dong-A University Research Fund. Informed consent was obtained from all individual participants included in the study. 


\section{References}

[1] Deveci, U., Barbaros, U., Kapakli, M.S., et al. (2013) The Comparison of Single Incision Laparoscopic Cholecystectomy and Three Port Laparoscopic Cholecystectomy: Prospective Randomized Study. Journal of the Korean Surgical Society, 85, 275-282. https://doi.org/10.4174/jkss.2013.85.6.275

[2] Khambaty, F., Brody, F., Vaziri, K. and Edwards, C. (2011) Laparoscopic versus single-incision cholecystectomy. World Journal of Surgery, 35, 967-972. https://doi.org/10.1007/s00268-011-0998-6

[3] Barbaros, U. and Dinccag, A. (2009) Single Incision Laparoscopic Splenectomy: The First Two Cases. Journal of Gastrointestinal Surgery, 13, 1520-1523. https://doi.org/10.1007/s11605-009-0869-8

[4] Navarra, G., Pozza, E., Occhionorelli, S., Carcoforo, P. and Donini, I. (1997) One-Wound Laparoscopic Cholecystectomy. The British Journal of Surgery, 84, 1627. https://doi.org/10.1002/bjs.1800840536

[5] Chuang, S.H., Chen, P.H., Chang, C.M. and Lin, C.S. (2013) Single-Incision vs Three-Incision Laparoscopic Cholecystectomy for Complicated and Uncomplicated Acute Cholecystitis. World Journal of Gastroenterology, 19, 7743-7750. https://doi.org/10.3748/wjg.v19.i43.7743

[6] Markar, S.R., Karthikesalingam, A., Thrumurthy, S., Muirhead, L., Kinross, J. and Paraskeva, P. (2012) Single-Incision Laparoscopic Surgery (SILS) vs. Conventional Multiport Cholecystectomy: Systematic Review and Meta-Analysis. Surgical Endoscopy, 26, 1205-1213. https://doi.org/10.1007/s00464-011-2051-0

[7] Puzziello, A., Orlando, G., Siani, C., et al. (2012) From 3-Port to New Laparoendoscopic Single-Site (LESS) Cholecystectomy: A Critical Analysis of Available Evidence. Surgical Innovation, 19, 364-369. https://doi.org/10.1177/1553350611436282

[8] Chow, A., Purkayastha, S., Aziz, O., Pefanis, D. and Paraskeva, P. (2010) Single-Incision Laparoscopic Surgery for Cholecystectomy: A Retrospective Comparison with 4-Port Laparoscopic Cholecystectomy. Archives of Surgery, 145, 1187-1191. https://doi.org/10.1001/archsurg.2010.267

[9] Tsimoyiannis, E.C., Tsimogiannis, K.E., Pappas-Gogos, G., Farantos, C., Benetatos, N., Mavridou, P., et al. (2010) Different Pain Scores in Single Transumbilical Incision Laparoscopic Cholecystectomy versus Classic Laparoscopic Cholecystectomy: A Randomized Controlled Trial. Surgical Endoscopy, 24, 1842-1848. https://doi.org/10.1007/s00464-010-0887-3

[10] Lee, H.Y., Roh, Y.H., Kim, K.H., et al. (2012) Comparing of the Results between Single Port and Three Ports in Laparoscopic Cholecystectomy. Hepato-Gastroenterology, 59, 1761-1764. https://doi.org/10.5754/hge11003b

[11] Mendoza, D., Newman, R.C., Albala, D., et al. (1996) Laparoscopic Complications in Markedly Obese Urologic Patients (a Multi-Institutional Review). Urology, 48, 562-567. https://doi.org/10.1016/S0090-4295(96)00231-2

[12] Uslu, H.Y., Erkek, A.B., Cakmak, A., et al. (2007) Trocar Site Hernia after Laparoscopic Cholecystectomy. Journal of Laparoendoscopic \& Advanced Surgical Techniques, 17, 600-603. https://doi.org/10.1089/lap.2006.0182

[13] Gollan, J.L., Bulkley, G.B., Diehl, A.M., et al. (1993) NIH Consensus Conference: Gallstones and Laparoscopic Cholecystectomy. JAMA, 269, 1018-1024. https://doi.org/10.1001/jama.1993.03500080066034

[14] Sreenivas, S., Mohil, R.S., Singh, G.J., Arora, J.K., Kandwal, V. and Chouhan, J. (2014) Two-Port Mini Laparoscopic Cholecystectomy Compared to Standard 
Four-Port Laparoscopic Cholecystectomy. Journal of Minimal Access Surgery, 10, 190-196. https://doi.org/10.4103/0972-9941.141517

[15] Pan, M.X., Jiang, Z.S., Cheng, Y., et al. (2013) Single-Incision vs Three-Port Laparoscopic Cholecystectomy: Prospective Randomized Study. World Journal of Gastroenterology, 19, 394-398. https://doi.org/10.3748/wjg.v19.i3.394

[16] Cheng, Y., Jiang, Z.S., Xu, X.P., et al. (2013) Laparoendoscopic Single-Site Cholecystectomy vs. Three-Port Laparoscopic Cholecystectomy: A Large-Scale Retrospective Study. World Journal of Gastroenterology, 19, 4209-4213. https://doi.org/10.3748/wjg.v19.i26.4209

[17] Teubner, O., Heidecke, C.D., Kohlmann, T., Ludwig, K. and Patrzyk, M.A. (2016) Prospective Study Comparing Quality of Life and Cosmetic Results between Single-Port and Conventional Laparoscopic Cholecystectomy. Surgical Science, 7, 114-125. https://doi.org/10.4236/ss.2016.72016

[18] Wu, S., Lv, C., Tian, Y., Fan, Y., Yu, H., Kong, J., et al. (2016) Transumbilical Single-Incision Laparoscopic Cholecystectomy: Long-Term Review from a Single Center. Surgical Endoscopy, 30, 3375-3385. https://doi.org/10.1007/s00464-015-4618-7

[19] Tacchino, R., Greco, F. and Matera, D. (2009) Single-Incision Laparoscopic Cholecystectomy: Surgery without a Visible Scar. Surgical Endoscopy, 23, 896-899. https://doi.org/10.1007/s00464-008-0147-y

[20] Lee, P.C., Lo, C., Lai, P.S., et al. (2010) Randomized Clinical Trial of Single-Incision Laparoscopic Cholecystectomy versus Mini Laparoscopic Cholecystectomy. British Journal of Surgery, 97, 1007-1012. https://doi.org/10.1002/bjs.7087

[21] Marks, J., Tacchino, R., Roberts, K., et al. (2011) Prospective Randomized Controlled Trial of Traditional Laparoscopic Cholecystectomy versus Single-Incision Laparoscopic Cholecystectomy: Report of Preliminary Data. The American Journal of Surgery, 201, 369-373. https://doi.org/10.1016/j.amjsurg.2010.09.012

[22] Lee, Y., Roh, Y., Kim, M., Kim, Y., Kim, K., et al. (2018) Analysis of Post-Operative Complication in Single-Port Laparoscopic Cholecystectomy: A Retrospective Analysis in 817 Cases from a Surgeon. Journal of Minimal Access Surgery. https://doi.org/10.4103/jmas.JMAS_168_17

[23] Ma, J., Cassera, M.A., Spaun, G.O., Hammill, C.W., Hansen, P.D. and Aliabadi-Wahle, S. (2011) Randomized Controlled Trial Comparing Single-Port Laparoscopic Cholecystectomy and Four-Port Laparoscopic Cholecystectomy. Annals of Surgery, 254, 22-27. https://doi.org/10.1097/SLA.0b013e3182192f89

[24] Garg, P., Thakur, J.D., Raina, N.C., Mittal, G., Garg, M. and Gupta, V. (2012) Comparison of Cosmetic Outcome between Single-Incision Laparoscopic Cholecystectomy and Conventional Laparoscopic Cholecystectomy: An Objective Study. Journal of Laparoendoscopic \& Advanced Surgical Techniques. Part A, 22, 127-130. https://doi.org/10.1089/lap.2011.0391

[25] Koo, E.J., Youn, S.H., Baek, Y.H., et al. (2012) Review of 100 Cases of Single Port Laparoscopic Cholecystectomy. Journal of the Korean Surgical Society, 82, 179-184. https://doi.org/10.4174/jkss.2012.82.3.179

[26] Tay, C.W., Shen, L., Hartman, M., Iyer, S.G., Madhavan, K. and Chang, S.K. (2013) SILC for SILC: Single Institution Learning Curve for Single-Incision Laparoscopic Cholecystectomy. Minimally Invasive Surgery, 2013, Article ID: 381628. https://doi.org/10.1155/2013/381628

[27] Amanda, J., Douglas, I., Marc, D. and Michael, A. (2009) The Learning Curve with Single-Port Cholecystectomy. JSLS, 13, 332-336. 


\section{Appendix 1}

\section{Patient Assessment Questionnaire}

Single port ( )/Three port ( )

\section{Patient information}

1) What is your gender? (Male/Female)

2) How old is your age? ( years old)

3) What is your height? ( $\mathrm{cm}$ )

4) What is your weight? ( $\mathrm{kg}$ )

\section{Social aspects}

1) Are you satisfied with your physical condition after surgery?

(1) Very satisfied (1) Satisfied (1)Moderate (1) Dissatisfied (1) Very dissatisfied

2) Do you think this surgery give you a limit on your nutrition?

(1) Extremely (1) Quite a bit (1)Moderately (1) A little bit (1) Not at all

3) Do you think your stamina has decreased after surgery?

(1) Extremely (1) Quite a bit (1)Moderately (1) A little bit (1) Not at all

4) Are postoperative pain levels acceptable?

(1) Extremely (1) Quite a bit (1)Moderately (1) A little bit (1) Not at all

5) Do you think this surgery and recovery process give you somewhat constrained to return your social activities?

(1) Extremely (1) Quite a bit (1)Moderately (1) A little bit (1) Not at all

6. Do you think this surgery is somewhat impaired your social life after surgery?

(1) Extremely (1) Quite a bit (1)Moderately (1) A little bit (1) Not at all

7) How do you think about the degree of complications of surgery you experienced?

(1) Not at all (1) Slightly (1) Moderately (1) Severe (1)Very Severe

8) What do you think about the cost-effectiveness of this surgery?

(1) Very cheap (1) Cheap (1) Moderate (1) Expensive(1)Very expensive

\section{Cosmetic aspects}

1) Do you think the surgical wounds (scars) affect your outward charm??

(1) Extremely (1) Quite a bit (1)Moderately (1) A little bit (1) Not at all

2) Are you satisfied with the appearance of your scars?

(1) Very satisfied (1) Satisfied (1) Moderate (1)Dissatisfied (1) Very dissatisfied

3) How many points if you give marks to your scars?

$\begin{array}{llllllllll}1 & 2 & 3 & 4 & 5 & 6 & 7 & 8 & 9 & 10\end{array}$

( $1=$ Very severe scarring $10=$ Almost no scarring) (Score:

4) Have you had problems in everyday life because of surgical wounds(scars)??

(1) Extremely (1) Quite a bit (1)Moderately (1) A little bit (1) Not at all

Thank you for your answering the questions. 